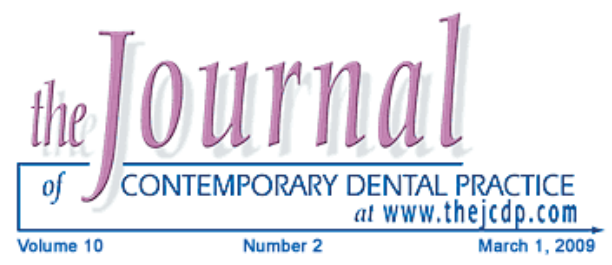

\title{
Microleakage of an Adhesive System used as a Fissure Sealant
}
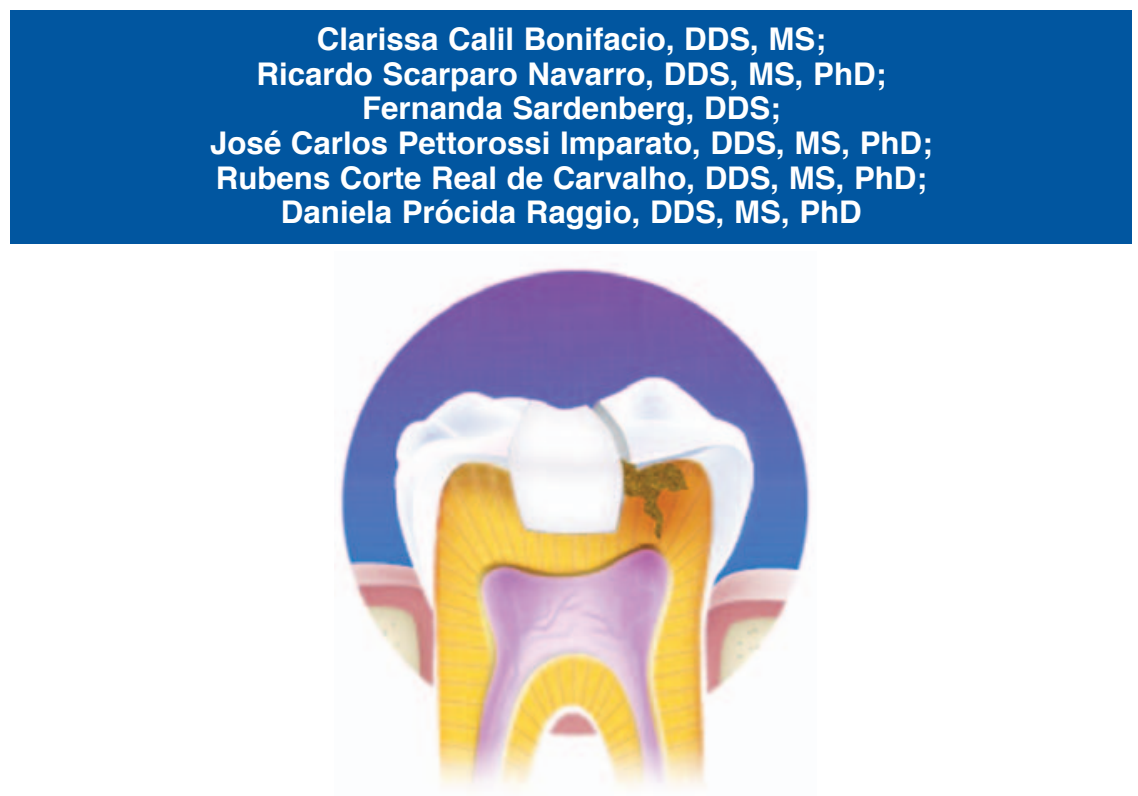

Abstract

Aim: The aim of this study was to investigate the microleakage of pit and fissure sealants in primary teeth and to determine if multi-step methods should produce better results in terms of microleakage prevention.

Methods and Materials: A total of 40 intact primary molars were randomly assigned to one of four sealant groups: resin based sealant Ultraseal XT (US - Ultradent) (Group 1, n=10); adhesive system Scotchbond Multi Purpose Plus (SBMP - 3M/ESPE) used as a sealant (Group 2, $n=10$ ); primer (SBMP) and US (Group 3, $n=10$ ); and primer, bond (SBMP) and US (Group 4, $n=10)$. After thermocycling $\left(x 700,5-55^{\circ} \mathrm{C}\right)$ all teeth surfaces were made impermeable with the exception of the occlusal surface. Samples were immersed in $50 \%$ silver nitrate for 8 hours, sectioned longitudinally with two cuts in the central fissure pit, and then immersed in photo development solution followed by 16 hours in fluorescent light. Pictures were obtained by light microscope (x40) and the degree of microleakage was evaluated by three blinded evaluators. The data were analyzed using the Kruskal Wallis test.

Results: Significant statistical differences $(\mathrm{p}<.05)$ were observed between Groups 1-3, Groups 2-3, Groups 2-4, and Groups 3-4. Group 3 showed higher microleakage scores.

Conclusion: The adhesive system and the resin based sealant demonstrated similar microleakage properties, suggesting the possibility that adhesives can be used in a clinical setting. Additionally, the increase in the

(c) Seer Publishing 
number of clinical steps required by common application of resin based sealant, including use of primer or primer and bond, did not lead to better results in preventing microleakage.

Clinical Significance: The adhesive system can be used as a sealant without increasing the microleakage. Thus, the use of the adhesive system before the application of the sealant is not necessary to reduce the microleakage, although further research is warranted to support this conclusion.

Keywords: Sealant, microleakage, pit and fissure, adhesive system, laboratory research

Citation: Bonifacio CC, Navarro RS, Sardenberg F, Imparato JCP, Carvalho RCR, Raggio DP. Microleakage of an Adhesive System used as a Fissure Sealant. J Contemp Dent Pract 2009 March; (10)2:026-033.

\section{Introduction}

The success of pit and fissure sealants over long time spans depends on an effective marginal seal, retention, and integrity. Ideally, low viscosity resin sealant should fill porosities and irregularities of enamel rods created after acid etching, promoting effective bond strength to the substrate and leading to long-term clinical durability. Sealant microleakage is a very undesirable incident that suggests failure of the adhesion process.

Sealants are used to reduce the biofilm retention in occlusal areas that are difficult to clean (due to restricted access) and in oral cavities with poor hygiene and/or high caries risk. ${ }^{2}$ Sealants are also used therapeutically in carious lesions and not only as a preventive method. ${ }^{1,2}$ The sealant can be used on incipient caries lesions inactivating the carious process. The sealant forms a physical barrier between microflora and nutrients of the oral environment, inhibiting the cariogenic microbiota and the lesion progression.

The use of an adhesive system before application of the resin sealant could reduce imperfections in material penetration into enamel substrate. The bond strength of a sealant applied after the adhesive system in a saliva-contaminated surface is equivalent to the bond strength of a sealant applied on a dry surface. ${ }^{3,4}$ Due to the difficulty of using a rubber dam and humidity control in some clinical situations, it is recommended to use an adhesive system, as the primer (hydrophilic) allows better penetration in the humid substrate, opening space to the sealant and ensuring proper results. $^{5}$
The application of the adhesive system prior to sealant increases the number of clinical steps and procedure time. Thus, the study of marginal sealing of an adhesive system used as a pit and fissure sealant or associated to sealant becomes relevant due to questioning of its clinical efficiency.

Some studies demonstrated adhesive systems can act as a substitute for the resin sealants to seal fissures. ${ }^{6,7}$ Therefore, it may be possible to simplify the technique of preventive resin restoration by using the adhesive agent as a fissure sealant.

The aim of this study was to compare the microleakage of different sealant materials applied in sound pits and fissures of occlusal surfaces in primary molars. The sealants used in the study were: (Group 1) a resin sealant; (Group 2) an adhesive system (primer + bond)

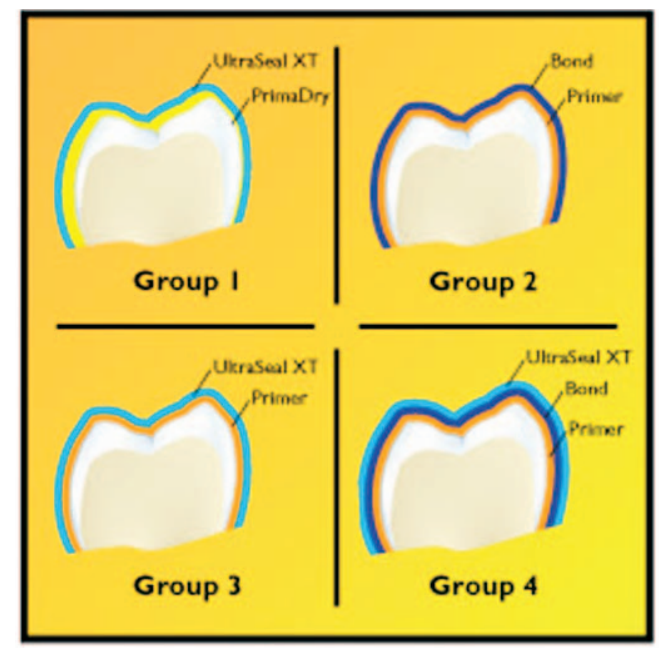


used as sealant; (Group 3) a sealant used after previous application of primer, and (Group 4) a sealant used after previous application of primer and bond. Furthermore, analyses on the tradeoff between the increase in the number of clinical steps and better results in preventing microleakage were carried out.

\section{Methods and Materials}

Forty non-carious, intact primary molars, obtained from the Human Tooth Bank at the University of São Paulo (Ethical Committee Approval 184/04) were cleaned with pumice and Robinson brush in low-speed hand piece and washed with water. The pits and fissures were etched with 37\% phosphoric acid (Ultraetch/Ultradent, South Jordan, UT, USA) for 15 seconds, rinsed with water for 20 seconds, and air dried for 30 seconds.

Specimens were randomly assigned to one of four groups $(n=10)$ of sealant materials: (Group 1) resin based sealant - control; (Group 2) adhesive system (primer and bond) used as a sealant; (Group 3) primer and resin based sealant; and (Group 4) primer, bond, and resin based sealant.

The resin based sealant Ultraseal XT (Ultradent, South Jordan, UT, USA) in Group 1 was used after PrimaDry (a primer indicated by the manufacturer). PrimaDry was applied for 5 seconds, gently blown without rinsing, and the sealant was applied and light cured for 20 seconds. The adhesive system used in Groups 2, 3, and 4, was Scotchbond Multi Purpose Plus (3M/ESPE, St. Paul, MN, USA), applied with Microbrush (Microbrush ${ }^{\oplus}$ International, Grafton, WI, USA) in all extensions of the occlusal surface. Primer was applied and dried gently for 5 seconds. Adhesive was then applied and light cured for 10 seconds in Groups 3 and 4.

The materials were light cured using a XL 1500 (3M/ESPE, St. Paul, MN, USA) halogen lamp ${ }^{8}$ with intensity ranging from 400 to $600 \mathrm{~mW} / \mathrm{cm}^{2}$, as recommended for polymerization of resin composites. A radiometer was used to standardize the lamp intensity (Demetron Research Corporation, Danbury, CT, USA). The samples were stored in distilled water at $37^{\circ} \mathrm{C}$ for 24 hours and later thermocycled $\left(x 700,5^{\circ} \mathrm{C}\right.$ to $55^{\circ} \mathrm{C}$, dwell time 60 seconds) in order to simulate the thermal conditions, creating stress on tooth-restoration interface.
Specimens were made impermeable using cyanoacrylate ester (Super Bonder, Henkel Loctite Products, Rocky Hill, CT, USA) in the root apex. Two nail polish layers (Impala, Guarulhos, SP, Brazil) were applied to all tooth surfaces, with the exception of the occlusal surface. The four groups were differentiated by the color of nail polish.

After 24 hours of water storage, the specimens were immersed in a silver nitrate solution $(50 \%$ by weight) and kept in complete darkness and at room temperature for 8 hours. Subsequently, they were rinsed in tap water for 1 minute and left on absorbent paper for 2 hours.

The specimens were embedded in a chemically activated acrylic resin with a silicone model Sample-Kwick (Buehler Ltd., Lake Bluff, IL, USA), previously isolated with petroleum jelly. When the resin polymerization was completely achieved, the specimens were longitudinally sectioned in a mesio-distal direction, with two cuts in the central fissure pit by the use of a Labcut machine (Extec Corp, Enfield, CT, USA), with a diamond disc, cooled with water, at $250 \mathrm{rpm}$.

After cutting, specimens were immersed in pure photo development solution (Kodak) for 16 hours under fluorescent light to facilitate reduction of silver ions to metallic silver.

With the cut side facing up, the samples were put on a flat surface so their images could be captured by a light microscope (x40) (Leica, Wetlzar, Germany). Three evaluators examined the images and identified the possible existence of spaces in the interface of sealant/tooth as being a potential marginal microleakage. Evaluators were previously trained and blind in relation to the groups. The images were evaluated in the same computer screen by all evaluators.

The examiners assigned values to the penetration of the tracer agent according to the scale proposed by Grande et al. ${ }^{9}$

$0=$ No penetration of the tracer agent (Figure 1a)

$1=$ Penetration of the tracer agent in the superficial interface enamel/sealant (Figure 1b)

$2=$ Penetration of the tracer agent in all extension of the interface sealant/enamel (Figure 1c)

$3=$ Penetration of the tracer agent in all 
extension of the interface sealant/enamel reaching the portion below of the sealant (Figure 1d)

These standardized scores were assigned by the evaluators and repeated three times, 120 readings for each examiner, totaling 360 score values.

The data were analyzed using a GMC program (GMC version 7.5, Ribeirão Preto, SP, Brazil) and Kruskal-Wallis test $(p<0.05)$ to determine the statistical significant of the differences between groups.

\section{Results}

The mean microleakage score for each group is shown in Figure 2.

Data analysis found statistically significant differences between: sealant (Group 1) x primer + sealant (Group 3); primer + bond + sealant (Group 4) $\times$ primer + bond (Group 2); primer + bond + sealant (Group 4) x primer + sealant (Group 3); and primer + bond (Group 2) x primer + sealant (Group 3). Higher microleakage values were found in Group 3, where only primer and sealant had been used, and lower values were found in Group 1 (sealant) and Group 4 (primer, bond, and sealant). Group 2 (primer and bond) demonstrated higher microleakage than Group 1 and Group 4 but less microleakage than Group 3 (primer and sealant).

\section{Discussion}

Troubridge ${ }^{10}$ defined microleakage as the oral fluid penetration in gaps created between dental structure and restorative material. According to the author, the main causes of microleakages are adaptation problems and shrinkage of sealing material to the dental substrate. The physical/ chemical alterations and the occlusal forces clearly intervene in the microleakage process.

Sealants are indicated mainly while the tooth is in eruption as effective cleaning may be difficult." However, proper isolation of the region is not always possible during tooth eruption. A significant problem in the clinical use of resin sealants is contamination with saliva. To reduce the deleterious effect of contamination of the enamel in the adhesion process some authors have advocated the application of adhesive systems prior to sealant placement. ${ }^{7,12,13}$ Ultraseal XT's instructions
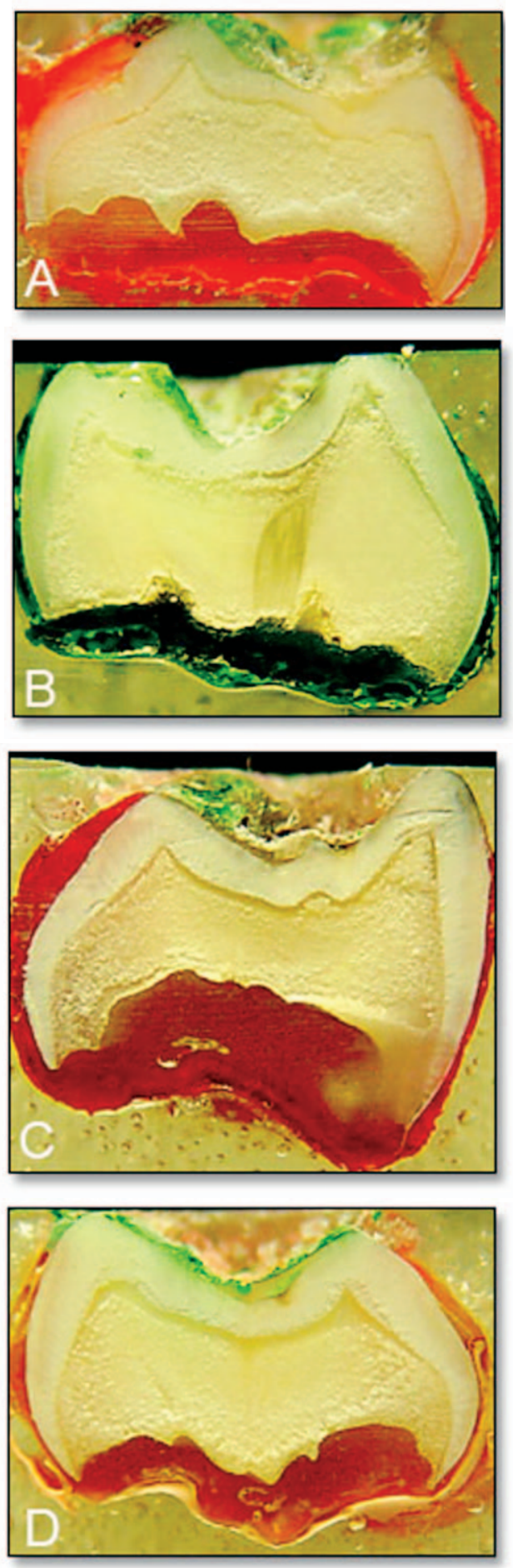

Figure 1. Examples of the standardized scores. A. Score 0. B. Score 1. C. Score 2. D. Score 3. 


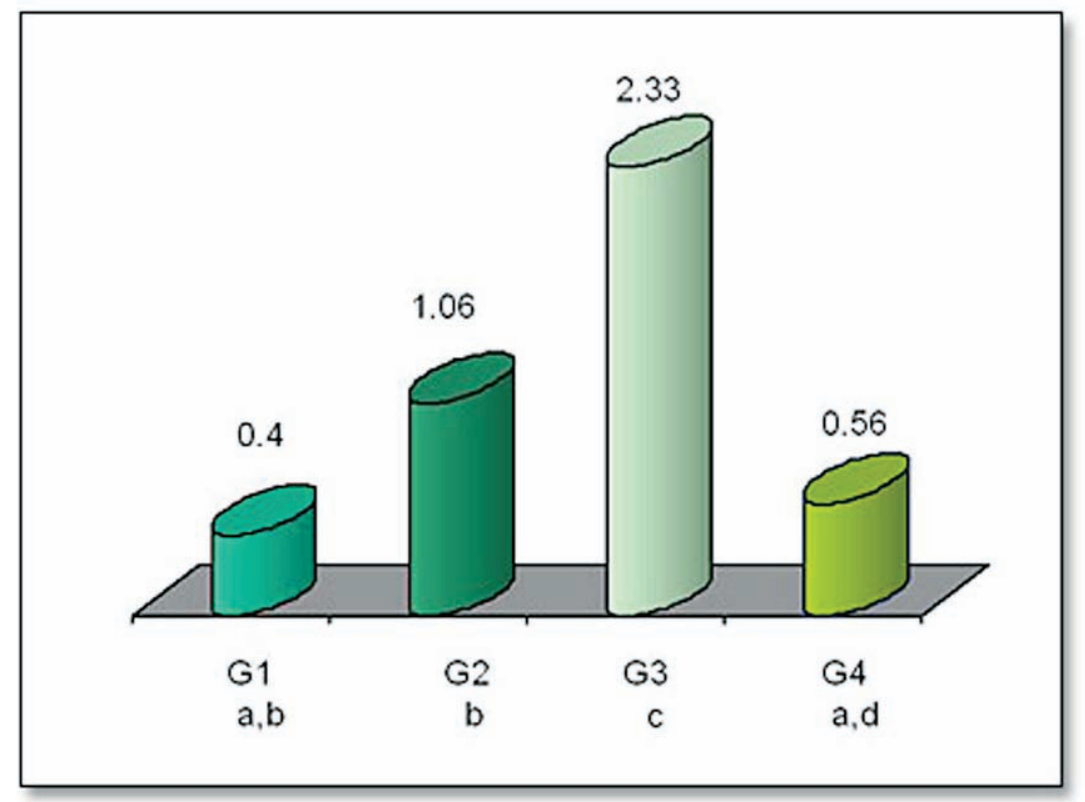

Figure 2. Mean microleakage scores. Different letters indicate statistical difference $(p<0.05)$.

advise using PrimaDry, a drying agent, to solve this problem. An alcohol based liquid with a hydrophilic monomer, PrimaDry bonds to the water molecules contained in the tooth's pits and fissures, creating a chemical linkage and essentially volatilizing them. This effect is evidenced by the freezing aspect of the enamel after the application.

The use of PrimaDry can be considered a superficial energy reestablishment agent. Therefore, as well as primers, PrimaDry allows for a satisfactory draining of the sealant. The aim of the primer is to increase the wettability of the sealant, allowing higher penetration in the interprismatic spaces. ${ }^{9}$ In Group 1, where PrimaDry and Ultraseal XT were used, lower microleakage values were found with a statistically significant difference only compared to Group 3 (primer and sealant).

The use of adhesive systems as pit and fissure sealants is reported throughout the literature as the use of these systems increases the bond strength of sealant to the surface of the enamel surface and improves its penetration in the depth of the fissure. , $^{5,14,15}$

When the resin sealant is associated with an adhesive system, an excellent marginal sealing is found ${ }^{5,16}$ The present research agrees with the literature findings, as statistically significant differences were not found between Group 1 (sealant) and Group 2 (primer and bond) and between Group 1 and Group 4 (primer, bond, and sealant). This finding shows the use of adhesive systems allows adequate marginal sealing. Even if the adhesive system does not necessarily improve the marginal sealing of the resin based sealant, it at least does not provoke a deleterious effect. Yet the use of this adhesive system, Scotchbond Multipurpose Plus, as a sealant produced good results in relation to the presence of microleakage.

The primary inspiration for this study was to improve the quality of tooth sealing. The fact there are alternatives for traditional (resin based) sealants using adhesive systems before application or by substituting them for the resin based sealant motivated the association of adhesive systems or primers to sealant. The interest in improving the quality of tooth sealing is maintained in the scope of the study despite the additional clinical steps needed with the use of adhesive systems or primers. Increasing the number of clinical steps implies keeping the environment dry for longer and higher professional dexterity. Generally the teeth to be sealed are in infra-occlusion so the use of a 
rubber dam is made even more difficult and can contribute to significantly higher procedure costs.

Most of the studies that investigated the use of adhesive systems as sealants dealt with a contaminated environment, as teeth selected for sealant are normally in eruption and proper isolation with a rubber dam is not achievable. Consequently, some authors suggest the use of an adhesive system as sealant can prevent contamination with saliva. ${ }^{5,12}$

Microleakage analyses are relevant as they can verify the capacity of the sealing material to penetrate into pits and its ability to establish good marginal sealing. Additional factors can interfere in the material's penetration property, such as the anatomy of the tooth, the adjusted enamel acid etching, and the correct prophylaxis to prevent the accumulation of biofilm or other contaminants that can hinder good draining materials. ${ }^{17}$

The use of a sealant after the application of the Scotchbond Multipurpose Plus primer was found not to have good marginal sealing as there were statistically significant differences in microleakage between Group 3 (primer and sealant) when compared with all other groups (Group 1 and Group 3; Group 2 and Group 3; and Group 3 and Group 4).

Scotchbond Multipurpose Plus primer is composed of a watery solution of HEMA and a polymer of a polyalkenoic acid. Therefore, this is a good material to be used in a humid substrate as it induces the formation of ionic linkage between calcium of the tooth and the polyalkenoic acid of the primer. PrimaDry is a hydrophilic alcohol based monomer, which is used to prepare the surface that will receive the sealant. The sealant UltraSeal XT is composed by a hydrophilic monomer, which possibly does not interact with the primer's polymer of polyalkenoic acid from Scotchbond.

Clinically, the correct isolation of teeth during eruption is not feasible, though, they are the teeth that normally need sealing. Therefore, for procedures with additional clinical steps the paradox between appropriate isolation and need for isolation is even more explicit, as the isolation is required for a longer period. In the present study, increasing the number of clinical steps did not provide better marginal sealing between material and tooth, agreeing with studies by Cooley et al. ${ }^{3}$ and Boksman et al. ${ }^{4}$

Sealants, in the majority of cases, are needed during molar's eruption with the presence of white spots or in high caries risk. Glass ionomer cement would be better indicated for this situation. This material is ideal for sealing pits and fissures due to its chemical adhesion property to tooth and to release and uptake of fluoride. Different types of glass ionomers can be used for sealing, conventional type, resin modified ${ }^{18}$ or high viscosity, with great powder/liquid ratio. ${ }^{19,20}$ The main problem with glass ionomer sealants is the short retention time, on average six months. ${ }^{18}$ However, this should not always be seen as a disadvantage, as this duration is, many times, enough to decrease the invasive treatment to the tooth. After this short period, the patient could reduce the caries risk by cleaning the surface properly or the tooth could be already in occlusion, leading to biofilm disturbed by chewing.

Resin based sealants can also be indicated for sealing carious lesions because it isolates the dental plaque from the nutrients of the oral environment. With such a barrier the cariogenic microbiota cannot survive, bringing an end to the progression of the injury. For good marginal sealing, with fewer possibilities of microleakage, the resin based sealants are indicated more than glass ionomer sealants for carious lesions. This procedure is also called therapeutic sealing. ${ }^{2,21-23}$

\section{Conclusion}

The results of this study found adhesive systems and the resin based sealants demonstrated similar microleakage properties suggesting the possibility of using adhesive systems as sealants in the clinical setting. Additionally, the increase in the number of clinical steps required for common application of a resin based sealant, including use of primer or primer and bond, does not lead to better results in preventing microleakage.

\section{Clinical significance}

The adhesive system can be used as a sealant without increasing the microleakage. Thus, the use of the adhesive system before the application of the sealant is not necessary to reduce the microleakage, although, further research is warranted to support this conclusion. 


\section{References}

1. Mertz-Fairhurst EJ, Curtis JW Jr, Ergle JW, Rueggeberg FA, Adair SM. Ultraconservative and Cariostatic Sealed Restorations: Results at Year 10. J Am Dent Assoc 1998 Jan; 129(1):55-66.

2. Welbury R, Raadal M, Lygidakis NA, European Academy of Paediatric Dentistry. EAPD Guidelines for the use of pit and fissure sealants. Eur J Paediatr Dent 2004 Sep; 5(3):179-84.

3. Boksman L, Mcconnell RJ, Carson B, Mccutcheon-Jones EF. A 2-year clinical evaluation of two pit and fissure sealants placed with and without the use of bonding agent. Quintessence Int 1993 Feb; 24(2):131-3.

4. Cooley RL, Garcia-Godoy F, Ramly DM, Bruger KM. Effect of dentin adhesion on sealant bond strength. J Dent Res 1991; 70:571.

5. Hitt JC, Feigal RJ. Use of a bonding agent to reduce sealant sensitivity to moisture contamination: an in vitro study. Pediatr Dent 1992 Jan-Feb; 14(1):41-6.

6. Swift EJ. Dentin/enamel adhesives review of the literature. Pediatr Dent 2002, 24:456-61.

7. Baca P, Bravo M, Baca AP, Jimenez A, Gonzale-Rodrigues MP. Retention of three fissure sealants and a dentin bonding system used as fissure sealant in caries prevention: 12-month follow-up results. Med Oral Patol Oral Cir Bucal 2007; 12:459-63.

8. Rueggeberg FA, Caughman WF, Curtis Jr JW. Effect of light intensity and exposure duration on cure of resin composite. Oper Dent 1994; 19(1):26-32.

9. Grande RHM, Ballester RY, Singer JM, Santos JF. Microleakage of a universal adhesive used as a fissure sealant. Am J Dent 1998 Jun; 11(3):109-13.

10. Troubridge HO. Model systems for determining biologic effects of microleakage. Oper Dent 1987; 12(4):164-172.

11. Carvalho JC, Ekstrand KR, Thylstrup A. Dental plaque and caries on occlusal surfaces of first permanent molars in relation to stage of eruption. J Dent Res 1989 May; 68(5):773-9.

12. Hebling JC, Feigal RJ. Use of one-bottle adhesive as an intermediate bonding layer to reduce sealent microleakage on saliva-contaminated enamel. Am J Dent 2000; 13:187-91.

13. Duangthip D, Lussi A. Microleakage and penetration ability of resin sealant versus bonding system when applied follwing contamination. Pediatr Dent 2003; 25:505-11.

14. Dorignac GF. Efficacy of highly filled composites in the caries prevention of pits and fissures: two and one half years of clinical results. J Pedod 1987; 11(2):139-45.

15. Reid JS, Saunders WP, Chen YY. The effect of bonding agents and fissure sealant on microleakage of composite resin restorations. Quintessence Int 1991; 22(4):295-8.

16. Cooley RL, Garcia-Godoy F, Ramly DM, Bruger KM. Effect of dentin adhesion on sealant bond strength. J Dent Res 1991; 70:571.

17. Symons AL, Chu CY, Meyers IA. The effect of fissure morphology and pretreatment of the enamel surface on penetration and adhesion of fissure sealants. J Oral Rehabil 1996 Dec; 23(12):791-8.

18. Pardi V, Pereira AC, Mialhe FL, Meneghim MDE C, Ambrosano GM. A 5-year evaluation of two glassionomer cements used as fissure sealants. Community Dent Oral Epidemiol 2003; 31(5):386-91.

19. Frencken JE, Makoni F, Sithole WD. ART restorations and glass ionomer sealants in Zimbabwe: survival after 3 years. Community Dent Oral Epidemiol 1998; 26:372-81.

20. Holmgren CJ, Lo ECM, Hu DY, Wan H. ART restorations and sealants placed in Chinese school children - results after 3 years. Community Dent Oral Epidemiol 2000; 28:314-20.

21. Mertz-Fairhurst EJ, Richards EE, Williams JE, Smith CD, Mackert JR Jr, Schuster GS, Sherrer JD, O'Dell NL, Pierce KL, Wenner KK, Ergle JW. Sealed restorations: 5-year results. Am J Dent 1992 Feb;5(1):5-10.

22. Mertz-Fairhurst EJ, Adair SM, Sams DR, Curtis JW Jr, Ergle JW, Hawkins KI, Mackert JR Jr, O'Dell NL, Richards EE, Rueggeberg F, Russel CM, Schuster GS, Sherrer JD, Smith CD, Williams JE, Caughman WH, Dickinson GL. Cariostatic and ultraconservative sealed restorations: nine-year results among children and adults. ASDC J Dent Child. 1995 Mar-Apr; 62(2):97-107.

23. Hevinga MA, Opdam NJ, Frencken JE, Bronkhorst EM, Truin GJ. Microleakage and sealant penetration in contaminated carious fissure. J Dent. 2007 Dec;35(12):909-14. 


\section{About the Authors}

\section{Clarissa Calil Bonifacio, DDS, MS}

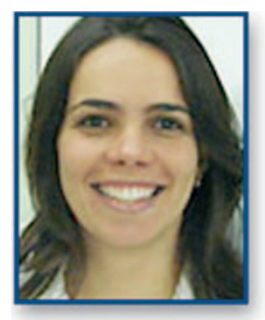

Dr. Bonifacio received her Masters degree in Restorative Dentistry from the Faculty of Dentistry at the Universidade de São Paulo in São Paulo, Brazil. Her research interests include pediatric dentistry, restorative minimum intervention treatments, glass ionomer cements, adhesion, and clinical trials.

e-mail: clarissacalil@usp.br

Ricardo Scarparo Navarro, DDS, MS, PhD

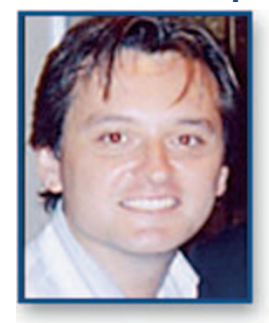

Dr. Navarro received a PhD in Pediatric Dentistry and a MS in Restorative Dentistry from the Faculty of Dentistry at the Universidade de São Paulo in São Paulo, Brazil. He serves as a Professor of Dental Materials and Restorative Dentistry at the Camilo Castelo Branco University in Sao Paulo, Brazil. His research interests include pediatric dentistry, caries prevention, laser in dentistry, dental materials, and restorative dentistry.

e-mail: ricardosnavarro@gmail.com

\section{Fernanda Sardenberg, DDS}

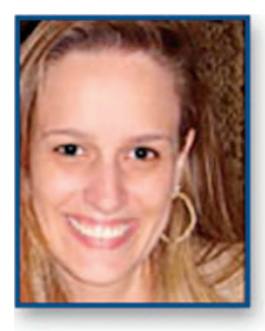

Dr. Sardenberg is a graduate student (Masters) in the Department of Pediatric Dentistry of the School of Dentistry at the Federal University of Minas Gerais in Minas Gerais, Brazil. Her research interests include pediatric dentistry, dental materials, and epidemiological surveys.

e-mail: fesardenberg@hotmail.com

\section{José Carlos Pettorossi Imparato, DDS, MS, PhD}

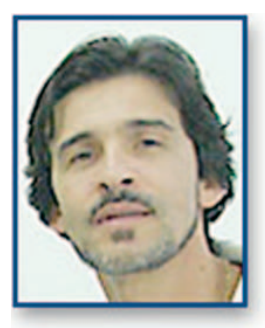

Dr. Imparato is an Assistant Professor in the Department of Pediatric Dentistry Faculty of Dentistry at the Universidade de São Paulo in São Paulo, Brazil. He is also a faculty member of the Department of Pediatric Dentistry, School of Dentistry at São Leopoldo Mandic in Campinas, SP, Brazil. His research interests include composite resin, adhesion, and pediatric dentistry.

\section{Rubens Corte Real de Carvalho, DDS, MS, PhD}

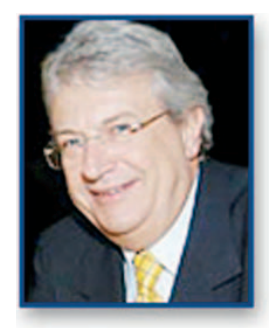

Dr. Carvalho is a Professor in the Department of Restorative Dentistry Faculty of Dentistry at the Universidade de São Paulo in São Paulo, Brazil. His research interests include restorative dentistry, dental bleaching, and clinical trials with dental materials.

e-mail: rcorte@usp.br 
Daniela Prócida Raggio, DDS, MS, PhD

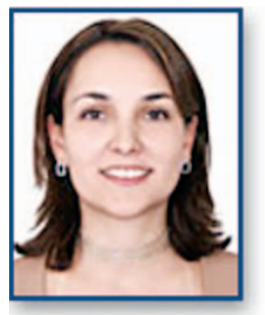

Dr. Raggio is an Assistant Professor in the Department of Pediatric Dentistry of the Faculty of Dentistry at the Universidade de São Paulo in São Paulo, Brazil. Her research interests include glass ionomer cements, ART, adhesion, and pediatric dentistry.

e-mail: danielar@usp.br 